\title{
Assessment and Countermeasures for Offshore Wind Farm Risks Based on a Dynamic Bayesian Network
}

\author{
Chunhui Zhou, Xin Liu, Langxiong Gan \\ Wuhan University of Technology, Wuhan, China \\ Email:441526916@qq.com
}

How to cite this paper: Zhou, C.H., Liu, X. and Gan, L.X. (2018) Assessment and Countermeasures for Offshore Wind Farm Risks Based on a Dynamic Bayesian Network. Journal of Environmental Protection, 9, 368-384. https://doi.org/10.4236/jep.2018.94024

Received: March 8, 2018

Accepted: April 27, 2018

Published: April 30, 2018

Copyright (@) 2018 by authors and Scientific Research Publishing Inc. This work is licensed under the Creative Commons Attribution International License (CC BY 4.0).

http://creativecommons.org/licenses/by/4.0/

\section{(c) () Open Access}

\begin{abstract}
Wind power is a kind of clean energy promising significant social and environmental benefits, and in The Peoples Republic of China, the government supports and encourages the development of wind power as one element in a shift to renewable energy. In recent years however, maritime safety issues have arisen during offshore wind power construction and attendant production processes associated with the rapid promotion and development of offshore wind farms. Therefore, it is necessary to carry out risk assessment for phases in the life cycle of offshore wind farms. This paper reports on a risk assessment model based on a Dynamic Bayesian network that performs offshore wind farms maritime risk assessment. The advantage of this approach is the way in which a Bayesian model expresses uncertainty. Furthermore, such models permit simulations and reenactment of accidents in a virtual environment. There were several goals in this research. Offshore wind power project risk identification and evaluation theories and methods were explored to identify the sources of risk during different phases of the offshore wind farm life cycle. Based on this foundation, a dynamic Bayesian network model with Genie was established, and evaluated, in terms of its effectiveness for analysis of risk during different phases of the offshore wind farm life cycle. Research results show that a dynamic Bayesian network method can perform risk assessments effectively and flexibly, responding to the actual context of offshore wind power construction. Historical data and almost real-time information are combined to analyze the risk of the construction of offshore wind power. Our results inform a discussion of security and risk mitigation measures that when implemented, could improve safety. This work has value as a reference and guide for the safe development of offshore wind power.
\end{abstract}

\section{Keywords}

Bayesian Network, Offshore Wind Farm, Risk Assessment, Countermeasures 


\section{Introduction}

Offshore wind power risks refer to risks posed by harsh environments at sea, generator set equipment failure, structural failure, management organization and socio-political issues. The characteristics of offshore wind power risk are as follows: the objective existence and ubiquity of risk, the uncertainty and predictability of risk, the variety of risk, the change of risk with force majeure, the natural risk is obviously higher, and the correlation between risk factors is larger. The stage of offshore wind power risk is apparent.

Bayesian network, also known as reliability network, is an extension of Bayesian method. It is one of the most effective theoretical models in the field of uncertain knowledge expression and reasoning. After being put forward by Pearl in 1988, it has become a research hotspot in recent years. A Bayesian network is a Directed Acyclic Graph (DAG) consisting of representative variable nodes and connected directed nodes. The nodes represent random variables. The directed edges between nodes represent the mutual relationships between nodes (pointed by the parent node to its child nodes). The conditional probability is used to express the strength of the relationship. No parent node uses the prior probability to express information. The node variable can be abstraction of any problem, such as test value, observation phenomenon, opinion inquiry, etc. Events that apply to the expression and analysis of uncertainties and probabilities are applied to decisions that are conditionally dependent on a variety of control factors and can be reasoned from incomplete, inaccurate, or uncertain knowledge or information.

Bayesian networks, especially dynamic Bayesian networks, take account of changes occurring over the life cycle phases of offshore wind farms, based on a large number of training sets and accident reports, and to some extent, reduce of the influence human subjective factors, making assessment results are more reliable and objective. Dynamic Bayesian network also has the time characteristics, to ensure continuity in the reasoning process before and after, so that the whole reasoning method looks more in line with the development of objective things. Dynamic Bayesian network can automatically retain the information when it is input, which can well combine the past data and the current evidence information, keep the time accumulation of the information storage, effectively reduce the uncertainty of the information fusion inference and improve the accuracy of information fusion.

GeNIe is supporting software developed by the University of Pittsburgh Decision Systems Laboratory. Using GeNIe could compute traditional influence diagram utility, and find the optimal strategy. GeNIe is implemented by Visual C++ and uses MFC (Microsoft Foundation Classes) for visualization. Because it runs on today's most popular computing platform: Windows operating systems, it makes it very simple and convenient. As long as it is within the limits of computer memory, GeNIe allows the creation of models of any size and any complexity [1]. 
With GeNIe tool to build a dynamic Bayesian risk assessment model for offshore wind farms in different phases of construction and production process, and analyze the assessment results, so as to put forward requirements and suggestions on safety protection in various aspects, so as to improve the construction and production of offshore wind farms security capabilities.

Section 2 of this paper introduces research related to dynamic Bayesian networks and offshore wind power safety. Section 3 discusses a novel dynamic Bayesian risk assessment model for phases in the offshore wind farm life cycle, and Section 4 discusses offshore wind power risk assessment strategies during each phase, the final section draws conclusions and presents directions for future research.

\section{Related Works}

I divide the related work into two categories: Bayesian Network and offshore wind farm. I have summed up the relevant work of the Bayesian network as follows:

The mechanism of how to determine the missing data type was discussed based on the analysis of some data samples lost in the control system. Zhu, Zhang [2] used the method of dynamic Bayesian network to model the general fault prediction problems in the control system and deal with the real-time fault prediction problems of nonlinear systems with missing data. The results show that although the data sample is noisy and partially missing, combined with the effective processing of missing data, dynamic Bayesian network can effectively predict the system fault.

Thompson [3] considered that dynamic Bayesian networks can effectively model and infer many dynamic systems. However, most of its reasoning algorithms involve complex graphic transformations, which are difficult to program and time-consuming. Therefore, they put forward a new recursive reasoning algorithm, which is a pure numerical method to deduce discrete model on-line and Off-line based on probability theory and Bayesian network characteristics.

Yu, Ying [4] applied the Bayesian network analysis method to the evaluation of battlefield situation, and the effectiveness of Bayesian network analysis method was proved by the reasoning of actual battlefield events and the evaluation of naval battlefield situation.

Chen, Wang, Rao [5] analyzed the applicability of Bayesian network analysis method. He Uses the method of David Chickering to combine the novel criterion, Variable ordering and equivalent class and combines the genetic algorithm and greedy algorithm in Bayesian network, proved the practicability of this method by simulation.

In addition, I have summed up the relevant work of the offshore wind farm as follows:

Aghaebrahimi, Mehdizadeh [6] used this method to model a wind farm as a multi-state conventional unit. A suitable time-series model-the auto-regressive 
moving average was employed in this study to predict wind speeds. Moreover, the reliability of offshore wind power is analyzed by Bayesian network.

Zhang, Zhang, Stua [7] analyzed the existing international policies and specific conditions and made a comprehensive evaluation according to the historical development of global offshore wind power. At the same time, he discusses the future development prospects of wind power in China and the problems it faces, and makes a specific study on the actual situation of the relevant enterprises in wind power development in China. Furthermore, some effective suggestions were put forward for the sustainable development of wind power in China.

\section{Construction of Dynamic Bayesian Risk Assessment Model}

\subsection{Dynamic Bayesian Network}

\subsubsection{Bayesian Network}

1) Probability theory (network)

Network is built on the basis of probability theory, in which the multiplication formula, Bayes' formula, the chain rule, conditional probability, total probability, etc. are often used in the theoretical system of Bayesian networks.

2) Bayesian networks

In a complete Bayesian network, the nodes in the network are used to replace the variables in the actual model. A directed arc is used to represent the relationship among variables. The direction of the directed arc is from the cause to the result node. A Bayesian network is actually a set of directed acyclic graphs and related parameters (Daly, R, Shen, Q, Aitken, S, 2011). The composition includes: a) In the network structure, an acyclic graph that is connected by directed arcs to represent the structure of the model; b) In the parameter setting, each variable has its corresponding conditional probability table, which is used to express dependencies between variables.

Thus, Let $X$ denote each node variable in the network and $\mathrm{Pa}$ denote the parent node set corresponding to a certain node $X$ in the model. Then, the joint probability of all the variables in the model is expressed as formula (1):

$$
P(X)=\prod_{i=1}^{n} P\left(X_{I} / P a_{i}\right)
$$

Let us construct a simple Bayesian network as shown in Figure 1, where A is

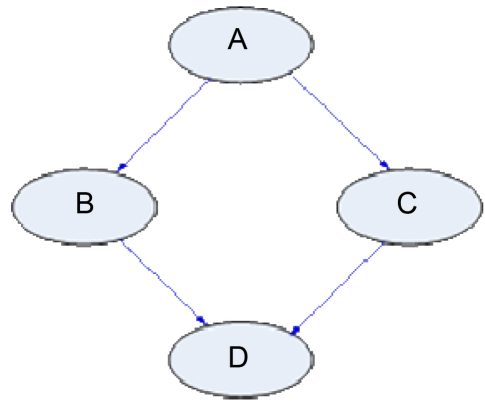

Figure 1. A simple Bayesian network. 
the parent node of B and C, and D is the child node of B and C.

3) The determination of Bayesian network parameters

Considering the sources of risk in a hypothetical scenario of a rotor-blade accident, we set the two states of network node as occurrence/non-occurrence (logically true/false) with two states; "0" and " 1 ". To determine the parameters of a Bayesian network for accident risk assessment, we use historical, rotor-blade accident data reported in a reference (WIND TURBINE ACCIDENT AND INCIDENT COMPILATION). We evaluated the prior information of each likely risk source to determine the parameters for each node in the network.

At the same time, in order to obtain the posterior probability in the Bayesian network, a large number of Conditional Probability Tables (CPTs) in the network must be determined in advance. To determine the conditional probability table is the basis for the next step of Bias network inference. This research uses accident reports as the sample data, combining expert experience to generate conditional probability tables that correspond to each node of the network. In order to ensure that the conditional probability values for each node are more close to the actual situation, based on the statistical analysis of the data, using a Bayesian expectation estimation method; At the same time, combined with the results of the expert questionnaire survey, the two parties are weighted to determine the condition probability. The formulation of a node conditional probability table, is based on the reality of the fan accident made statistical analysis, in which each sample the result of the accident will cause the fan accident broke out, which makes the research of objectivity and authenticity, so the phenomenon that the probability of risk become larger will occur when probabilistic inference.

\subsubsection{Dynamic Bayesian Network}

The dynamic Bayesian network is an extension of the Bayesian network. It not only can express the causality between variables as well as Bayesian network, but also can describe the evolution of a variable state in time sequence (Zheng, Gao, 2008). A dynamic Bayesian network can model and analyze a sequence of events, as shown in Figure 2.

The variable $X_{t}=\left\{C_{t}, M_{t}, O_{t}\right\}$ in Figure 2 has a probability dependency that varies with time $t=1,2, \cdots, n, \forall t, C_{t} \Rightarrow M_{t}, C_{t} \wedge M_{t} \Rightarrow O_{t}$, the joint probability distribution of variable $X_{i}$ is:

$$
P\left(X_{t}\right)=P\left(C_{t}, M_{t}, O_{t}\right)=P\left(C_{t}\right) P\left(M_{t} / C_{t}\right) P\left(O_{t} / C_{t}, M_{t}\right)
$$

Consider the conditional probability between $O_{t}$ and $C_{t}$ :

$$
\begin{aligned}
P\left(O_{t} / C_{t}\right) & =\frac{P\left(O_{t}, C_{t}\right)}{P\left(C_{t}\right)}=\frac{\sum_{m} P\left(O_{t}, C_{t}, M_{t}=m\right)}{P\left(C_{t}\right)} \\
& =\frac{\sum_{m} P\left(C_{t}\right) P\left(M_{t}=m \mid C_{t}\right) P\left(O_{t} \mid C_{t}, M_{t}=m\right)}{P\left(C_{t}\right)} \\
& =P\left(M_{t}=m \mid C_{t}\right) P\left(O_{t} \mid C_{t}, M_{t}=m\right)
\end{aligned}
$$




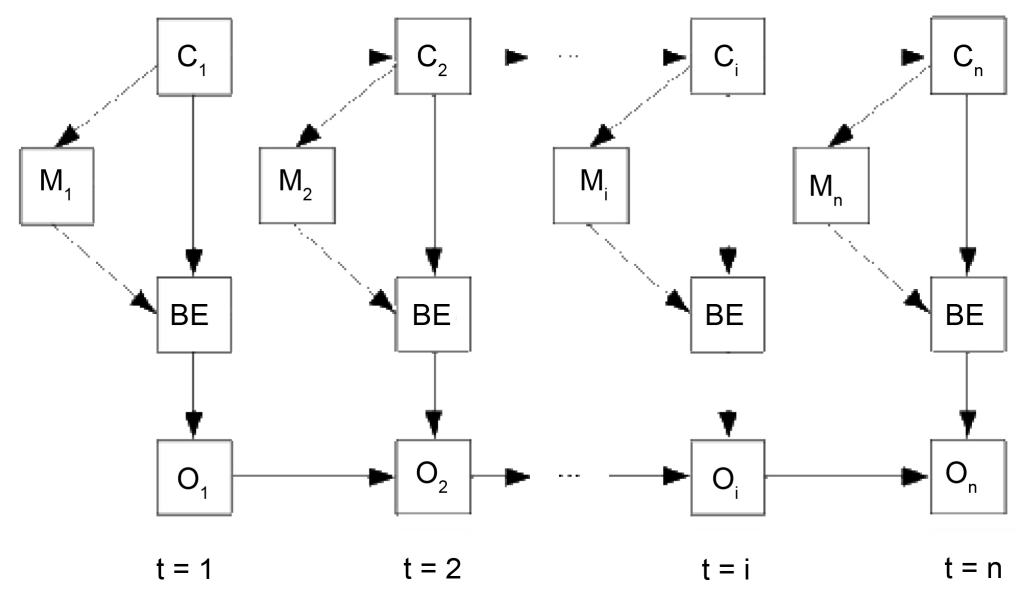

Figure 2. Dynamic bayesian network composition.

Between moments $t-1$ and $t$, the state of the variable set $C_{t}$ shifts, so the transition probability of the variable set $X_{t}$ is:

$$
P\left(X_{t} \mid X_{t-1}\right)=P\left(C_{t} \mid C_{t-1}\right)
$$

A dynamic Bayesian network can not only model the dependence of features corresponding to variables, but also the temporal relationship between the features, and the probability dependency among the variables through the network topology and changes over time. Thus, it is suitable for the modeling of complex characteristics of offshore wind power generation that are both feature-dependent and time-dependent.

\subsection{GeNIe Tools}

GeNIe was designed by the University of Pittsburgh Decision Systems Laboratory. It is software used to build theoretical models for graphical decision-making. The GeNIe interface is an easy and powerful way to build Bayesian network models, widely used in project research and commercial applications. This software eliminates the computational complexity for researchers and simplifies the work steps, supporting the work of academics using Bayesian networks to study uncertainty across many domains.

\section{Life Cycle Phases of Offshore Wind Farms for Risk Assessment}

Comprehensive risk assessment of offshore wind farms involves analysis and assessment of various types of uncertain factors from the design phase through operations, but especially during the future operation phase. Marine risk identification is the first step in the risk assessment. The various factors that affect offshore wind power must be analyzed to determine the types of risks and the factors influencing safe operations. The proposed Bayesian network for risk assessment method for offshore wind farms targets four life cycle phases: the planning phase, construction phase, operation and maintenance phase, and disposal 
phase.

\subsection{Construction of Dynamic Bayesian Networks for Risk Assessment of Offshore Wind Farms}

The establishment of a general dynamic Bayesian network model is rather complicated. Before establishing a model, it is necessary to make assumptions and simplifications. In this paper, we make the following assumptions about dynamic Bayesian networks:

Hypothesis 1: Within a finite time, change in the conditional probability for all $\mathrm{t}$ is stable and consistent;

Hypothesis 2: The process of dynamic probability can be described as a Markov chain. The probability of occurrence of future events is stochastic, having nothing to do with past events, but only with the current moment;

Hypothesis 3: Conditional probability processes remain stable at adjacent times, that is, probability and time have no relation.

\subsection{Construction of Planning Phase in Bayesian Network}

In this paper, the methods of historical data analysis, brainstorming, and expert judgment combined with the Delphi method are used to identify potential risks.

According to the expert questionnaire survey, it is determined that the risk factors of offshore wind power construction and production in the planning phase are as follows: 1 ) the site selection criteria; 2 ) the distance between factors waterway, navigation route and anchorage; 3) site selection and planning compliance; 4) submarine cable routing arrangement; 5) seabed and geological exploration; 6) ocean hydrological meteorological conditions assessment. Each category also contains a number of risk factors. The Bayesian network model of risk assessment in this phase is shown in Figure 3.

\subsection{Establishing the Construction Phase in a Bayesian Network}

According to historical accident data and expert questionnaire survey, the risk factors of offshore wind power in construction and production construction phase are determined as Table 1.

\subsection{Construction of Operation and Maintenance Phase in Bayesian Network}

According to historical accident data and expert questionnaire survey, the risk factors of offshore wind power construction and production operation and maintenance phases are determined as Table 2.

\subsection{Construction of Disposal Phase in Bayesian Network}

According to the historical accident data and expert questionnaire survey, the risk factors of offshore wind farms during the abandonment phase are determined as Table 3. 


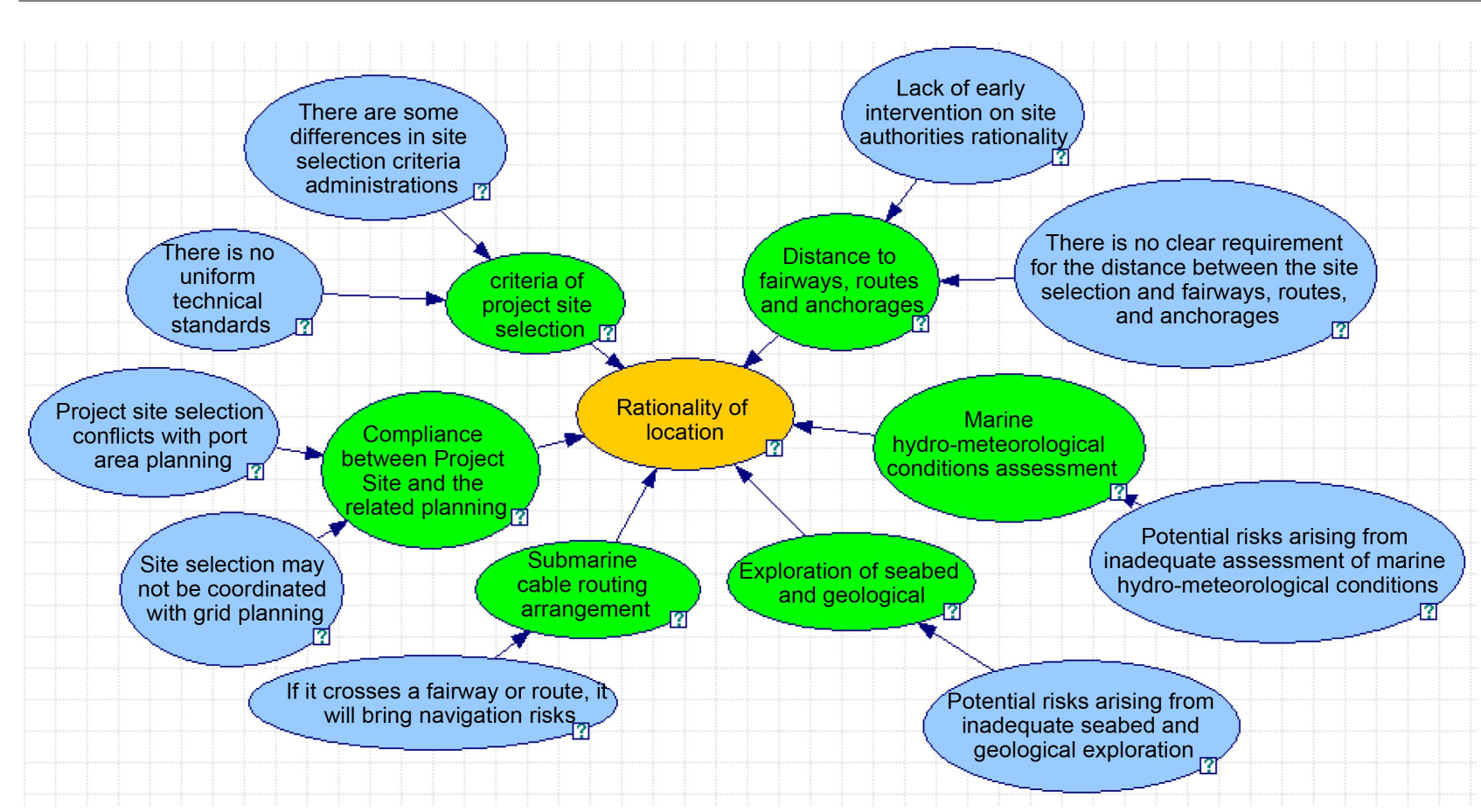

Figure 3. Bayesian network model for risk assessment during planning phase.

\section{Risk Assessment at Different Life-Cycle Phases}

\subsection{Determination of Node Parameters}

The node parameters are the states of the nodes or the states of different states when the states of the nodes are uncertain. Since most of the risk factors studied in this paper are in an indefinite state, this paper focuses on the method of determining the node parameters when the node state is uncertain. It is noteworthy that in a complete Bayesian network assessment model, the node parameters only need to get the parameters of the basic node.

In the entire Bayesian network, there are nine nodes in the planning phase, there are 27 Bayesian nodes in the construction phase, there are 26 Bayesian nodes in the operation and maintenance phase. Network node parameters in disposal phase include 27; construction phase of the basic node as shown in Table 4.

Conditional probability table can obtain all node parameters except the base node.

The parameters of the basic nodes in the four phases are generally obtained from the data. When there is no relevant data for reference, it is necessary to utilize 2057 wind farm accidents collected at home and abroad for nearly 30 years (582 of which are in construction phase and 1328 in operation and maintenance phase, 147 in disposal phase) and the form of expert judgment to determine the node parameters. The frequency of occurrence of the risk factor in an accident is the probability of occurrence of the node.

According to the above methods, the node parameters of the risk factors of the construction phase, operation and maintenance phase and disposal phase of 
Table 1. Risk factors in construction phase.

\begin{tabular}{|c|c|}
\hline $\mathrm{S} / \mathrm{N}$ & Risk factors \\
\hline 1 & casualties; \\
\hline 2 & falling into the water; \\
\hline 3 & the construction workers knocking on and off; \\
\hline 4 & slipping; \\
\hline 5 & collision; \\
\hline 6 & stranded; \\
\hline 7 & fire disaster; \\
\hline 8 & wind disaster; \\
\hline 9 & take the anchor; \\
\hline 10 & installation accidents of wind tower, fan, booster station; \\
\hline 11 & access standards for construction workers is not clear; \\
\hline 12 & construction workers not certified; \\
\hline 13 & construction workers training is not enough; \\
\hline 14 & poor overall quality of compared to professional crew; \\
\hline 15 & crew not fit; \\
\hline 16 & unconscious of duties; \\
\hline 17 & non-compliance with safe operating procedures; \\
\hline 18 & operational errors; \\
\hline 19 & overlooked negligence; \\
\hline 20 & not comply with the rules of navigation; \\
\hline 21 & construction ships access standards are not clear; \\
\hline 22 & construction units choose type of ships casually; \\
\hline 23 & the lack of professional equipment for construction ships; \\
\hline 24 & high requirements for the ship's airworthiness; \\
\hline 25 & overloading phenomenon of transport vehicles and other transport is serious; \\
\hline 26 & imperfect life-saving facilities of construction ship; \\
\hline 27 & fishing boats in the construction area to walk through; \\
\hline 28 & accident caused by windy weather; \\
\hline 29 & the source of weather forecasts is not accurate; \\
\hline 30 & weather forecast is not timely; \\
\hline 31 & the depth of intertidal zone varies greatly; \\
\hline 32 & sudden bad weather; \\
\hline 33 & sheltered anchor distance; \\
\hline 34 & weak safety awareness of construction workers; \\
\hline 35 & imperfect emergency plan; \\
\hline 36 & emergency plan is not operational; \\
\hline 37 & emergency plan is not comprehensive; \\
\hline 38 & response is not timely, from an accident into danger; \\
\hline 39 & life-saving is not in time; \\
\hline 40 & limited construction operation conditions are not clear; \\
\hline
\end{tabular}




\section{Continued}

$\begin{array}{cc}41 & \text { the lack of necessary warning signs configuration; } \\ 42 & \text { no effective monitoring system; } \\ 43 & \text { maritime communications liaison is not satisfactory; } \\ 44 & \text { offshore search and rescue forces are relatively weak; } \\ 45 & \text { many shipping companies and management difficulties; } \\ 46 & \text { lack of effective communication and cooperation between construction } \\ 47 & \text { unit and construction unit; } \\ & \text { difficult to effectively cover maritime regulatory power. }\end{array}$

the base node can be determined. Since no traffic accident occurs in the planning phase, the node parameters of the base node are determined by expert judgment. Node parameters as shown in Table 4.

\subsection{Determination of Bayesian Conditional Probability}

In Bayesian networks, the Bayesian conditional probability table is the link between the reaction nodes and the nodes. When the state of a node cannot be known, the probability of the basic node can be determined by hydrological, meteorological data and the prior probability, while the intermediate node and the top node need to be determined by the conditional probability table.

Conditional probability table to obtain generally two ways, one is to use a large number of accident data to learn from Bayesian network, then get the conditional probability table; the other is to use the expert questionnaire to obtain the conditional probability table. After verifying the reliability of the conditional probability table obtained from the expert questionnaire, the paper will use historical accident data to optimize it and verify the effectiveness of the optimization.

This article collected a total of 2057 records of accidents (WIND TURBINE ACCIDENT AND INCIDENT COMPILATION), after a detailed analysis of the accident process, the nodes in the Bayesian network, which are at risk of sunk failure as reflected in the accident process, are counted. Considering that there are some not-so-reasonable parts of the conditional probability table based solely on historical accident data, which is due to failure to obtain the complete cause of the accident from the accidental data, resulting in missing base nodes in the Bayesian network and the middle node affects the accuracy of the conditional probability table. Based on the experience of a large number of experts in the field, it is very important to optimize and perfect the conditional probability table to make up for the possible error caused by the data learning of simple accident.

In order to make expertise more reliable, we need not only to collect expert opinions as much as possible, but also to ensure that the experts surveyed are with good knowledge and rich experience in the field of shipping industry. The experts in this research include a Professor and Doctor in the field of shipping 
Table 2. Risk factors in operation and maintenance phase.

\begin{tabular}{|c|c|}
\hline $\mathrm{S} / \mathrm{N}$ & Risk factors \\
\hline 1 & casualties; \\
\hline 2 & falling into the water; \\
\hline 3 & bumping into and out of operation and maintenance personnel; \\
\hline 4 & slipping people; \\
\hline 5 & submarine cable damage; \\
\hline 6 & collision; \\
\hline 7 & fire; \\
\hline 8 & wind disaster; \\
\hline 9 & wind tower, fan, booster station operational accident; \\
\hline 10 & operation and maintenance personnel access standards is not clear; \\
\hline 11 & operation and maintenance personnel not certified; \\
\hline 12 & operation and maintenance personnel training is not in place; \\
\hline 13 & non-compliance with safe operating procedures; \\
\hline 14 & crew not fit; \\
\hline 15 & unconscious of duties; \\
\hline 16 & low physical and mental qualifications; \\
\hline 17 & operational errors; \\
\hline 18 & overlooked negligence; \\
\hline 19 & not comply with the rules of navigation; \\
\hline 20 & the lack of professional operation and maintenance vessels; \\
\hline 21 & transport vessels and other transport vessels overloaded seriously; \\
\hline 22 & the lack of awareness of safety and security of operation and maintenance personnel; \\
\hline 23 & inadequate life-saving facilities; \\
\hline 24 & fishing vessels traveling freely in the work area; \\
\hline 25 & windy weather causing accidents; \\
\hline 26 & lightning weather incidents; \\
\hline 27 & inaccurate sources of weather forecast; \\
\hline 28 & weather forecasts are not timely; \\
\hline 29 & sudden bad weather; \\
\hline 30 & imperfect safety operation rules; \\
\hline 31 & imperfect emergency plan; \\
\hline 32 & emergency plan is not operable; \\
\hline 33 & emergency plan is not comprehensive; \\
\hline 34 & response is not timely from an accident into danger; \\
\hline 35 & rescue is not timely; \\
\hline 36 & qualification conditions of operation and maintenance are not clear; \\
\hline 37 & the lack of necessary warning signs configuration; \\
\hline 38 & no effective monitoring system; \\
\hline 39 & maritime communications liaison is not satisfactory; \\
\hline 40 & the force of offshore search and rescue is relatively weak; \\
\hline 41 & it is difficult to effectively cover maritime regulatory forces. \\
\hline
\end{tabular}


Table 3. Risk factors in disposal phase.

\begin{tabular}{|c|c|}
\hline $\mathrm{S} / \mathrm{N}$ & Risk factor \\
\hline 1 & casualties; \\
\hline 2 & falling into the water; \\
\hline 3 & the construction workers knocking on and off; \\
\hline 4 & slipping; \\
\hline 5 & collision; \\
\hline 6 & stranded; \\
\hline 7 & fire; \\
\hline 8 & wind disaster; \\
\hline 9 & Take the anchor; \\
\hline 10 & installation accidents of wind tower, fan, booster station; \\
\hline 11 & access standards for construction workers is not clear; \\
\hline 12 & construction workers not certified; \\
\hline 13 & construction workers training is not enough; \\
\hline 14 & poor overall quality of compared to professional crew; \\
\hline 15 & crew not fit; \\
\hline 16 & unconscious of duties; \\
\hline 17 & non-compliance with safe operating procedures; \\
\hline 18 & operational errors; \\
\hline 19 & overlooked negligence; \\
\hline 20 & not comply with the rules of navigation; \\
\hline 21 & construction ships access standards are not clear; \\
\hline 22 & construction units choose type of ships casually; \\
\hline 23 & the lack of professional equipment for construction ships; \\
\hline 24 & high requirements for the ship's airworthiness; \\
\hline 25 & overloading phenomenon of transport vehicles and other transport is serious; \\
\hline 26 & imperfect life-saving facilities of construction ship; \\
\hline 27 & fishing boats in the construction area to walk through; \\
\hline 28 & accident caused by windy weather; \\
\hline 29 & the source of weather forecasts is not accurate; \\
\hline 30 & weather forecast is not timely; \\
\hline 31 & the depth of intertidal zone varies greatly; \\
\hline 32 & sudden bad weather; \\
\hline 33 & sheltered anchor distance; \\
\hline 34 & weak safety awareness of construction workers; \\
\hline 35 & imperfect emergency plan; \\
\hline 36 & emergency plan is not operational; \\
\hline 37 & emergency plan is not comprehensive; \\
\hline 38 & response is not timely from an accident into danger; \\
\hline 39 & life-saving is not in time; \\
\hline
\end{tabular}




\section{Continued}

\begin{tabular}{cc}
\hline 40 & limited construction operation conditions are not clear; \\
41 & the lack of necessary warning signs configuration; \\
42 & no effective monitoring system; \\
43 & maritime communications liaison is not satisfactory; \\
44 & offshore search and rescue forces are relatively weak; \\
45 & many shipping companies and management difficulties; \\
46 & lack of effective communication and cooperation between \\
47 & construction unit and construction unit; \\
\hline
\end{tabular}

Table 4. The basic node parameter settings during construction phase.

\begin{tabular}{|c|c|c|c|}
\hline Node name & $\begin{array}{l}\text { The value of } \\
\text { node } \\
\text { Parameter (Y) }\end{array}$ & Node name & $\begin{array}{l}\text { The value of } \\
\text { node } \\
\text { parameter }(\mathrm{Y})\end{array}$ \\
\hline $\begin{array}{c}\text { construction workers } \\
\text { not certified }\end{array}$ & 0.1773 & $\begin{array}{l}\text { the source of weather } \\
\text { forecasts is not accurate }\end{array}$ & 0.0326 \\
\hline $\begin{array}{l}\text { construction workers } \\
\text { training is not enough }\end{array}$ & 0.3550 & $\begin{array}{l}\text { weather forecast } \\
\text { is not timely }\end{array}$ & 0.1137 \\
\hline poor overall quality & 0.1275 & $\begin{array}{c}\text { the depth of intertidal } \\
\text { zone varies greatly }\end{array}$ & 0.2378 \\
\hline unconscious of duties & 0.0889 & sheltered anchor distance & 0.3103 \\
\hline $\begin{array}{c}\text { weak safety } \\
\text { awareness of } \\
\text { construction workers }\end{array}$ & 0.1686 & $\begin{array}{l}\text { limited construction } \\
\text { operation conditions } \\
\text { are not clear }\end{array}$ & 0.5223 \\
\hline $\begin{array}{c}\text { non-compliance with safe } \\
\text { operating procedures }\end{array}$ & 0.2872 & response is not timely & 0.2619 \\
\hline operational errors & 0.0534 & $\begin{array}{l}\text { emergency plan is not } \\
\text { operational }\end{array}$ & 0.0533 \\
\hline $\begin{array}{c}\text { not comply with the rules } \\
\text { of navigation }\end{array}$ & 0.0469 & $\begin{array}{l}\text { emergency plan is not } \\
\text { comprehensive }\end{array}$ & 0.2275 \\
\hline overlooked negligence & 0.0584 & $\begin{array}{l}\text { the lack of necessary } \\
\text { warning signs configuration }\end{array}$ & 0.4155 \\
\hline $\begin{array}{l}\text { choose type of } \\
\text { ships casually }\end{array}$ & 0.2412 & weak force of rescue & 0.5189 \\
\hline $\begin{array}{c}\text { professional equipment is } \\
\text { not fully equipped }\end{array}$ & 0.3653 & $\begin{array}{l}\text { maritime communications } \\
\text { liaison is not satisfactory }\end{array}$ & 0.4567 \\
\hline $\begin{array}{l}\text { high requirements for the } \\
\text { ship's airworthiness }\end{array}$ & 0.1223 & $\begin{array}{c}\text { no effective } \\
\text { monitoring system }\end{array}$ & 0.6241 \\
\hline $\begin{array}{c}\text { overloading phenomenon } \\
\text { of transport vehicles and } \\
\text { other transport }\end{array}$ & 0.4550 & $\begin{array}{l}\text { difficult to effectively cover } \\
\text { maritime regulatory power }\end{array}$ & 0.2258 \\
\hline $\begin{array}{l}\text { imperfect life-saving } \\
\text { facilities of } \\
\text { construction ship }\end{array}$ & 0.4361 & I & \\
\hline
\end{tabular}


subjects, the captain and chief officer who has many years of sailing experience, and the front-line staff engaged in the construction and operation of the wind farm. With the combination of professionalism and practicality, the results of the questionnaire can be used as a consensus in the field.

From July 5th to July 8 th, 2017, the project team went to Huaneng Power Internation-al Co., Ltd. Jiangsu Branch, Jiangsu Offshore Longyuan Wind Power Co., Ltd., Jiangsu Longyuan Zhenhua Marine Engineering Co., Ltd., Xiangshui The Yangtze River Wind Power Co., Ltd., China Communications Third Navigation Engineering Bureau Co., Ltd. Jiangsu Branch, National Power Investment Group Binhai Offshore Wind Power Co., Ltd., and Huadian Heavy Industry Co., Ltd. to conducted a questionnaire survey.

150 questionnaires were distributed, 145 were collected, and 128 valid questionnaires were confirmed after screening. When calculating the actual probability, each expert will take the average of the corresponding interval. After statistics and calculation, one of the conditional probability tables (for example, "man-over-water" in the node of operation and maintenance phase) is shown in Table 5.

\subsection{Risk Assessment}

Since the risk assessment methods adopted in the four life-cycle phases are similar, this paper takes the planning phase as an example to assess the risk.

The base node probability of planning phase and the conditional probability of other nodes combined with historical accident learning and expert judgment are written into the Bayesian network model of risk assessment of planning phase in offshore wind farms. With the realization form of GeNIe software visualization, then get the Bayesian network of risk assessment during planning phase. As shown in Figure 4.

\subsection{Risk Assessment Results}

Design a questionnaire survey of experts, research the causes of the accident.

Table 5. Probability table for "man-over-water" conditions based on expert experience.

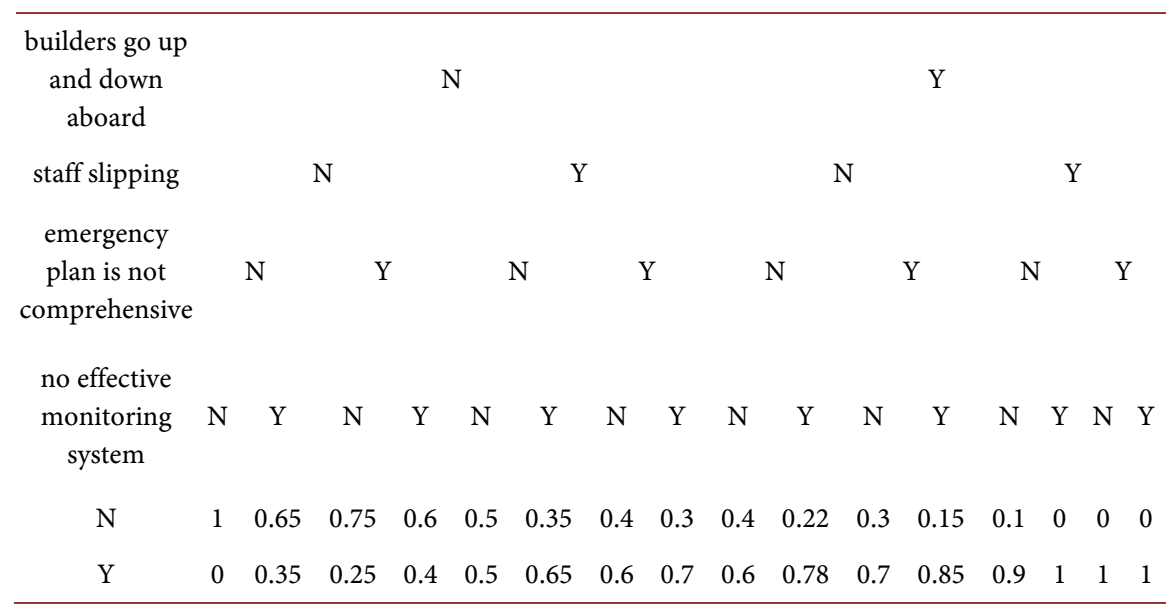




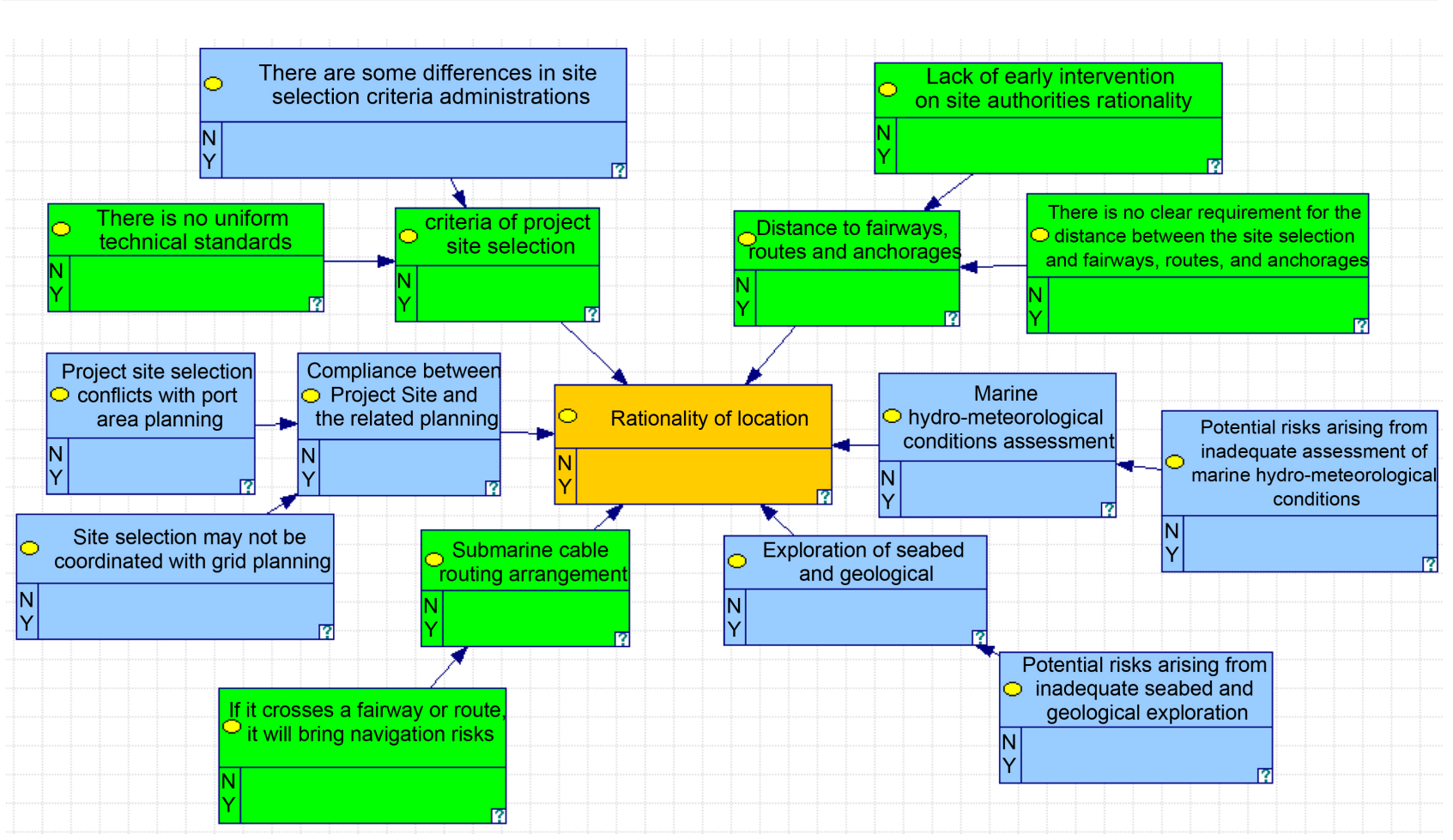

Figure 4. Risk assessment results of planning phase.

Through the research of domestic and international wind power accident investigation report, literature reading and wind power enterprises, expert judgment method, brainstorming method and historical data analysis method are used to identify the various stages of offshore wind farm risk source. According to the expert's view and combined with the experience of offshore wind power accidents to exclude the sources of risk that with small effect or no impact. The dynamic Bayesian network is used to analyze the accident factors and optimize the risk sources. The results are fed back to the experts, and the final verification is carried out.

The assumptions made in this paper for a dynamic Bayesian network are established. Expert experience can make up for missing nodes to a certain degree, but only through expert surveys to determine the conditional probability will lead to the subjectivity of the entire Bayesian network. On this basis, the historical accident data is used to verify and optimize it, making the conditional probability more accurate.

\section{Conclusions}

Based on the analysis of the division and operation characteristics of offshore wind farms at all phases of construction and production, the paper investigates the wind power enterprises, investigation reports of global wind power accidents and consults relevant literatures. By using expert judgment method, brainstorming method and historical data analysis method identify the risk sources at each phase. With Bayesian network dynamic assessment model and GeNIe visu- 
alization software, the modeling and assessment of each phase of offshore wind farm construction and production are carried out.

On the basis of risk identification and assessment, from the rationality and importance of site selection of offshore wind farm construction, operation qualification of construction (operation and maintenance), access conditions of ships (construction vessels, operation and maintenance vessels), personnel (constructors, operation and maintenance personnel), guidance and warning signs and the provision of safety supervision and other aspects of the requirements and recommendations for safety and security measures. We put forward requirements for emergency handling of wind turbine accidents, collisions, stranding, fire and explosion that may occur during the construction and production of offshore wind power.

After completion of this study, we can submit a complete offshore wind power development and production of maritime regulatory standards as well as offshore wind power production safety guidelines for the construction and assessment results. We can provide theoretical support for the construction of maritime wind power and production of maritime regulation and standardization of security.

\section{Acknowledgements}

This thesis is based on the offshore wind power project from School of Navigation Wuhan University of Technology as a theoretical support, and I would like to thank the project for providing theoretical support and experimental data for me, I can successfully write this thesis. Thanks to the scholars who brought me references, I am grateful to them for bringing me many references so that I can have reference in the process of writing essays.

\section{References}

[1] Huang, Y.Q. (2008) Research on Risk Assessment of Software Projects Based on BP Neural Network. China University of Petroleum (East China), Qingdao.

[2] Zhu, J.L. and Zhang, Z.D. (2012) Fault Prognosis for Data Incomplete Systems: A Dynamic Bayesian Network Approach. Key Laboratory of Advanced Process Control for Light Industry, Ministry of Education, Jiangnan University, Wuxi, 6.

[3] Thompson, C.P. (2009) Novel Recursive Inference Algorithm for Discrete Dynamic Bayesian Networks. Progress in Natural Science, 19, 1147-1151. https://doi.org/10.1016/j.pnsc.2008.10.015

[4] Yu, Y.T. and Ying, D. (2014) Improved Dynamic Bayesian Networks in Sea-Battlefield Situation Assessment. Shanghai Jiao Tong University, East China University of Science and Technology, Shanghai University of Engineering Science, Engineering and Industry Technology Institute, Shanghai, 6.

[5] Chen, F., Wang, X.F. and Rao, Y.M. (2007) Learning Bayesian Networks Using Genetic Algorithm. This Project Was Supported by the National Natural Science Foundation of China (70572045). Journal of Systems Engineering and Electronics, 18, 142-147.

[6] Heshmati, A., Najafi, H.R., Aghaebrahimi, M.R. and Mehdizadeh, M. (2012) Wind 
Farm Modeling For Reliability Assessment from the Viewpoint of Interconnected Systems. Electric Power Components and Systems, 40, 257-272.

https://doi.org/10.1080/15325008.2011.631086

[7] Zhang, X.L., Zhang, D. and Stua, M. (2012) Kickoff of Offshore Wind Power in China: Playoffs for China Wind Power Development. Procedia Environmental Sciences, 12, 166-173. https://doi.org/10.1016/j.proenv.2012.01.262 